\title{
Women's mental health: acute impact of COVID-19 pandemic on domestic violence
}

\author{
Sabrine Sediri ${ }^{1,2}$ - Yosra Zgueb ${ }^{1,2} \cdot$ Sami Ouanes $^{3} \cdot$ Uta Ouali $^{1,2} \cdot$ Soumaya Bourgou ${ }^{2,4} \cdot$ Rabaa Jomli $^{1,2}$. \\ Fethi Nacef ${ }^{1,2}$
}

Received: 17 June 2020 / Accepted: 13 October 2020 / Published online: 17 October 2020

(C) Springer-Verlag GmbH Austria, part of Springer Nature 2020

\begin{abstract}
The coronavirus disease 2019 (COVID-19) pandemic created a situation of general distress. Although the focus has been initially more on the physical health during the pandemic, mental health concerns linked to the lockdown have quickly risen. This study aims to assess the effect of the COVID-19-related lockdown on Tunisian women's mental health and gender-based violence. An online survey was conducted, using the Depression Anxiety and Stress Scales (DASS-21) and the Facebook Bergen Addiction Scale (FBAS). We chose a female-exclusive social group on Facebook and used the snowball sampling method. A total of 751 participants originating from all the Tunisian regions completed the questionnaire. More than half of the participants (57.3\%) reported extremely severe distress symptoms, as per the DASS-21. Those who had a history of mental illness and who were allegedly abused during lockdown were found to have more severe symptoms of depression, anxiety, and stress. Around $40 \%$ of women reported problematic social media use. Violence against women also reportedly increased significantly during the lockdown (from 4.4 to $14.8 \%$; $p<0.001)$. Psychological abuse was the most frequent type of violence $(96 \%)$. Women who had experienced abuse before the lockdown were at an increased risk of violence during lockdown $(p<0.001 ; \mathrm{OR}=19.34$ [8.71-43.00]). To our knowledge, this is the first study that evaluates the acute impact of COVID-19 on mental health and violence against women in Tunisia, Africa, and the Arab world. It may be a sound basis for developing a more effective psychological intervention aimed at women in these regions.
\end{abstract}

Keywords Gender-based violence · Anxiety · Depression · Spouse abuse · Quarantine · Coronavirus

\section{Introduction}

The World Health Organization (WHO) declared COVID-19 a pandemic since March 2020 (Liu et al. 2020). Due to the

This article is part of the Topical Collection on Women's mental health during the Covid-19 pandemic

Edited by: Anita Riecher-Rössler

Sabrine Sediri

sedirisab@gmail.com

1 Psychiatry department (A) Razi Hospital, Cité des Orangers, 2010 La Manouba, Tunisia

2 Faculty of Medicine of Tunis, University Tunis El Manar, Djebal Lakhdar Street, 1006 Tunis, Tunisia

3 Department of Psychiatry, Hamad Medical Corporation, P.O. Box 3050, Doha, Qatar

4 Child Psychiatry Department Mongi Slim Hospital, 2046 Sidi Daoued, Tunisia importance of human-to-human transmission, social distancing and lockdown have been the control strategies adopted by most countries in the world (Adhikari et al. 2020). In Tunisia, immediately after horizontal transmission was confirmed, the government (Tunisian Republic Presidency 2020) officially announced a lockdown on March 22, 2020. This decision caused a significant change in the everyday life of Tunisians: travel or movement restriction, suspension of work and studies (Tunisian Republic Presidency 2020), prolonged and forced contact between family members, reduced means of entertainment, boredom, loss of contact with wider social circles, and economic difficulties (Marques et al. 2020). These factors might have led to the COVID-19 pandemic turning into a psychosocial crisis, in addition to it being a major physical health concern. Therefore, in addition to the COVID-19 pandemic being a major physical health concern, these factors may have led to it becoming a psychosocial crisis. Violence against women is a public health problem worldwide and a violation of human rights (Oram et al. 2017). During humanitarian crises such as wars, natural disasters, or epidemics, 
violence expands mainly to the detriment of the most vulnerable groups. The COVID-19 pandemic and the lockdown can trigger the onset of anxiety disorders and may lead to symptom exacerbation in those with pre-existing disorders (Chatterjee et al. 2020). It is widely accepted that women are the most affected, given that they are known to have a more anxious temperament: This trait-like phenotype is characterized by increased behavioral and physiological reactivity to mildly stressful stimuli (Akiskal and Akiskal 2005). In addition, several genetic, sociocultural, hormonal, and developmental factors can influence an individual's response to stress, and the biological role of gender remains a vulnerability factor to psychosocial stress (Wang et al. 2007). The aim of this article is to study the effect of the lockdown on mental health of Tunisian women and the possible impact of lockdown on violence against women. To our knowledge, this study is the first to evaluate the impact of lockdown during the COVID-19 pandemic on women's mental health and violence in Tunisia, Africa, and the Arab world.

\section{Methods}

\section{Settings and participants}

Our research was conducted using an online survey, between April 25 and May 6, 2020, 1 month after the Tunisian government announced the lockdown. We chose a female social group on Facebook and used the snowball sampling method. We initially selected five participants. Each one of them was asked to choose five women to send the questionnaire to. The other participants were contacted using the same method until data saturation was reached. Women were recruited homogeneously throughout all Tunisian regions to ensure a representative sample of the Tunisian women. The survey was anonymous. All participants were Arabic-speaking and living on Tunisian territory.

Since the survey was anonymous, a message encouraging the request for help and breaking the silence in case of violence was sent to the respondents, to which a detailed reminder of the support structures had been attached. These contacts included the following: the toll-free numbers provided by the Ministry of Women, Family and Childhood, the contact information of associations specialized in providing care to victims of violence, the numbers of the police brigade specialized in violence against women, as well as the numbers of the emergency police and emergency medical assistance services. The toll-free numbers of the Tunisian psychological support unit (Zgueb et al. 2020) managed by volunteer psychiatrists and psychologists have also been made available for psychological first aid interventions.

\section{Data collection}

We used an anonymous online questionnaire to collect sociodemographic information (age, marital status, number of children, geographical area), mental health status (history of mental illness and eventual treatments taken), information on lockdown conditions (changes in working activities), and COVID-19 risk status (no personal risk, under quarantine, COVID+).

\section{Psychometric assessment}

The Depression Anxiety and Stress Scales (DASS-21) is a quantitative 21-item screening tool to assess symptoms of depression, anxiety, and stress. The validated Arabic version was used (Ali et al. 2017). This instrument comprises three subscales.

The depression subscale (DASS-21 D): with the following categories for the total score - normal (0-9), mild depression (10-12), moderate depression (13-20), severe depression (21-27), and extremely severe depression (28-42).

The anxiety subscale (DASS-21 A): with the following categories for the total score-normal (0-6), mild anxiety (7-9), moderate anxiety (10-14), severe anxiety (15-19), and extremely severe anxiety (20-42).

The stress subscale (DASS-21 S) - with the following categories for the total score: normal (0-10), mild stress (11-18), moderate stress (19-26), severe stress (27-34), and extremely severe stress (35-42) (Tran et al. 2013).

The Facebook Bergen Addiction Scale (FBAS) is a selfadministered 6 -item scale that evaluates addiction to Facebook. Each item corresponds to one of the six central components of addiction according to Griffith's model: salience, mood modification, tolerance, withdrawal symptoms, conflict, and relapse (Andreassen et al. 2012). Each item consists of a 5-point Likert scale ranging from "very rarely" to "very often." The validated Arabic version was used (Ghali et al. 2019).

The history of domestic violence and its types before and during the lockdown were assessed by yes or no questions.

\section{Statistical analysis}

Data was analyzed using the Statistical Package for the Social Sciences (IBM SPSS 22.0). For qualitative variables, we calculated simple frequencies and relative frequencies (percentages). For the quantitative variables, we calculated means and standard deviations, and we determined the extreme values (minimum and maximum). Percentage comparisons were made by the Chi-square test. Odds ratios (ORs) and their 95\% confidence intervals (CIs) were calculated. Standard univariate/bivariate comparisons of continuous measures (ANOVA) were used to compare means. Pearson's 
correlation test (in case of normal distribution) and Spearman's correlation test (in case of non-normal distribution) were used to examine correlations between quantitative variables. A $p$ value of less than 0.05 was considered significant in all analyses.

\section{Ethics}

Study participants were provided with the numbers of all social services and as well as those of therapists to contact if needed.

Our study was approved by the Ethics Committee of Razi Hospital, Manouba (RPA 6/2020). It was conducted in accordance with the guidelines of the 1995 Helsinki Declaration and its revisions (General Assembly of the World Medical Association 2014).

\section{Results}

\section{General characteristics}

We received 948 responses; 197 questionnaires were incomplete and thus excluded. Therefore, the number of included responses was 751 . The age ranged from 18 to 69 years, and the mean age was $37( \pm 8.2)$ years. The majority of respondents $(69 \%, n=518)$ were married (Table 1). Only $38.7 \%$ $(n=291)$ continued to work during the lockdown (Table 3). Forty-nine women $(6.5 \%)$ had a history of mental illness (Table 3), out of whom three quarters were on psychiatric treatment. Antidepressants were the most prescribed psychotropic class $(72 \%)$.

\section{Women's mental health}

\section{DASS scores}

Anxiety, depression symptoms, and stress were found in about $85 \%$ of the women. More than half of participants had symptoms of extreme severity for the three axes of the DASS-21 scale. The DASS-21 subscales severity ratings are detailed in Table 2.

\section{Associations between DASS 21 scores, Facebook addiction, and socio-demographic characteristics}

We found a statistically significant negative correlation between the age of the respondents and depression ( $p=0.004$; Rho $=-0.11)$, anxiety $(p=0.009 ; \mathrm{Rho}=-0.09)$, and stress $(p=0.002 ;$ Rho $=-0.11)$ subscores. We did not find any correlation between the number of children or the COVID-19 risk status and any of the DASS-21 subscores. The associations of
Table 1 Demographic characteristics of the study participants

\begin{tabular}{|c|c|c|}
\hline Characteristics & Numbers $(n=751)$ & Ratio (\%) \\
\hline \multicolumn{3}{|l|}{ Age range } \\
\hline $18-25$ & 64 & $8.5 \%$ \\
\hline $26-35$ & 310 & $41.3 \%$ \\
\hline $36-45$ & 294 & $39.2 \%$ \\
\hline $46-55$ & 65 & $8.6 \%$ \\
\hline $56-65$ & 18 & $2.4 \%$ \\
\hline \multicolumn{3}{|l|}{ Marital status } \\
\hline Single & 189 & $25.2 \%$ \\
\hline Married & 518 & $69 \%$ \\
\hline Divorced & 40 & $5.3 \%$ \\
\hline Widowed & 4 & $0.5 \%$ \\
\hline \multicolumn{3}{|l|}{ Number of children } \\
\hline No children & 262 & $34.9 \%$ \\
\hline 1 child & 136 & $18.1 \%$ \\
\hline 2 children & 276 & $36.8 \%$ \\
\hline 3 children & 77 & $10.2 \%$ \\
\hline \multicolumn{3}{|l|}{ Educational level } \\
\hline Primary school & 108 & $14.4 \%$ \\
\hline Secondary school & 143 & $19 \%$ \\
\hline High school & 197 & $26.3 \%$ \\
\hline University level & 303 & $40.3 \%$ \\
\hline \multicolumn{3}{|l|}{ COVID-19 status } \\
\hline No particular risk & 713 & $95 \%$ \\
\hline Under quarantine & 32 & $4.2 \%$ \\
\hline Positive to COVID-19 & 6 & $0.8 \%$ \\
\hline \multicolumn{3}{|c|}{ Work outside of COVID-19 context } \\
\hline Yes & 620 & $17.4 \%$ \\
\hline No & 131 & $82.6 \%$ \\
\hline \multicolumn{3}{|l|}{ Employment status } \\
\hline Full-time employment & 330 & $43.9 \%$ \\
\hline Part-time employment & 136 & $18.1 \%$ \\
\hline Self-employed/freelance & 80 & $10.7 \%$ \\
\hline Student & 74 & $9.9 \%$ \\
\hline Unemployed/retired & 131 & $17.4 \%$ \\
\hline
\end{tabular}

other socio-demographic factors with DASS subscores are detailed in Table 3.

\section{Facebook addiction}

Scores of the Facebook Bergen Addiction Scale ranged from 6 to 30 , and the mean score was $16.49( \pm 5.4)$. Forty percent $(n=300)$ of respondents might have Facebook addiction, as per the scale. A significant positive correlation was found between Facebook addiction score and DASS scores of depression $(p=0.001, r=0.43)$, anxiety $(p=0.001, r=0.39)$, and stress $(p=0.001, r=0.41)$. 
Table 2 DASS- 21 subscales severity ratings

\begin{tabular}{llllll}
\hline$n(\%)$ & Extremely severe & Severe & Moderate & Mild & Normal \\
\hline Depression & $430(57.3 \%)$ & $47(6.3 \%)$ & $95(12.6 \%)$ & $46(6.1 \%)$ & $133(17.7 \%)$ \\
Anxiety & $430(57.3 \%)$ & $43(5.7 \%)$ & $55(7.3 \%)$ & $67(8.9 \%)$ & $156(20.8 \%)$ \\
Stress & $399(53.1 \%)$ & $83(11.1 \%)$ & $92(12.3 \%)$ & $41(5.5 \%)$ & $136(18.1 \%)$ \\
\hline
\end{tabular}

\section{Violence against women}

We found that violence against women increased during lockdown from 4.4 to $14.8 \%(p<0.001)$ (Table 3). Psychological violence seemed to be the most frequent type. Indeed, virtually all those who were abused (96\%) experienced psychological (emotional) violence, followed by economic $(41 \%)$ and then physical violence $(10 \%)$. Almost $90 \%(n=98)$ of those who experienced violence during the lockdown did not seek assistance. None of the women who experienced emotional abuse reported it. Violence during lockdown was associated with higher scores of depression, anxiety, and stress (Table 3). It was also associated with higher Facebook addiction scores as shown in Table 4. Women who were already experiencing violence before the pandemic seemed to have a higher rate of violence $(73 \%)$ during the lockdown (versus $12 \%$ among those who do not have a history of domestic violence) (Table 5).

\section{Discussion}

In this cross-sectional study about women's mental health during the COVID-19-related lockdown in Tunisia, we found that most participants reported a high level of distress symptoms $(57.3 \%$ had extremely severe anxiety and depressive symptoms, and $53.1 \%$ had extremely severe stress symptoms). A problematic use of Facebook (and probably social media in general) was found in $40 \%$ of participants. In addition, violence against women was found to have increased significantly during the lockdown. Those who had a history of mental illness and who were abused during the lockdown were found to have more severe symptoms of depression, anxiety, and stress. Women who had been abused before the lockdown seemed to be at a higher risk of violence during the lockdown.

Our study took place in the early phase of COVID-19 spread in Tunisia. This timing may explain why more than half of the women interviewed suffered from severe distress symptoms, since information about the virus during that period was still very limited. Similarly, in China, more than $70 \%$ of the population was found to have high levels of psychological symptoms when evaluated during the Level I Emergency Response (Tian et al. 2020).
Uncertainty about the future and fear of the unknown had a negative impact on the mental health (Brooks et al. 2020), especially as the pandemic has been going on for more than 2 months, at the time of writing of this manuscript. Several studies about the mental health impact of the COVID-19 pandemic reported an increased incidence of anxiety, depressive and obsessive symptoms (Banerjee 2020), irritability, acute stress reaction (Mengin et al. 2020; Röhr et al. 2020), fear of being infected, and infecting those around them.

Response and responsiveness to stress appear to be different by gender. Because of several underlying biological mechanisms, women may be more vulnerable to depression and anxiety disorders (Verma et al. 2011) and might be particularly affected by stressful events (Wang et al. 2020). Indeed, starting at puberty, the prevalence of major depressive episodes is higher in female subjects, suggesting a hormonal and biological role in the susceptibility to anxiety and depression (Elhai et al. 2020). Most of the time, the woman is the main caregiver and is more responsible for household tasks and for the care of children (Wenham et al. 2020). This burden could have increased due to the temporary closure of schools during the lockdown. In fact, being a young parent, being a first-time parent, having many children, or having infants has been reported as being a potential source of exhaustion and may lead to parental burnout (Vigouroux and Scola 2018). However, our results did not find any link between the number of children and the severity of distress symptoms.

Gender-based violence can be psychological, physical, sexual, or economic. The intimate partner was responsible for $40 \%$ of the cases of femicide in the world (Stöckl et al. 2013). Studies suggest that an abused woman has a higher risk of developing depressive symptoms (Mapayi et al. 2013), attempting suicide, a higher risk of physical conditions such as physical trauma, sexually transmitted infections, unwanted pregnancy, and low birth weight (Devries et al. 2013). Activists have sounded the alarm about the increase in violence against women during this pandemic (Campbell 2020). The United Nations Population Fund (UNFPA) predicted a 31 million increase in cases of gender-based violence if lockdown extends by 6 months and 15 million additional cases with each 3-month extension (Bellizzi et al. 2020). As our results have shown, violence against women has increased significantly during the lockdown. In addition, we found that abused women had more depressive, anxious, and stressful symptoms than those who were not. 
Because of the lockdown, support structures for victims of violence were of limited access (Mazza et al. 2020). The focus has been on the physical impact of the pandemic, often to the detriment of mental health. Those who were abused during the lockdown may have felt abandoned, with limited possibilities of assistance. In many cases, they had to stay in quarantine with their aggressors. Home, which is supposed to be a "shelter" from the COVID-19 pandemic, might have been perceived by these women as a source of distress and insecurity.

Furthermore, we found that women who were already experiencing violence before the pandemic had a higher rate of violence during lockdown $(p=0.001, \mathrm{OR}=19.34$, $95 \% \mathrm{CI}=8.71-42.97)$. Indeed, according to the WHO, past tolerance of violence is a perpetuating factor of genderbased violence (Gracia 2004). In our study, $78 \%$ of the cases of violence recorded during lockdown were de novo, i.e., women assaulted for the first time during the lockdown. In Tunisia, the Ministry of Women, Family and Childhood declared that during the lockdown, domestic violence increased seven-fold (Tunisian Republic Presidency 2020). An awareness campaign was carried out by the Ministry of Women, Family and Childhood and civil society. It included TV commercials, social media advertisements, videos, and informative texts. Representatives of civil society presented on the topic in the most influential television programs in Tunisia. Collaboration between the Ministry of Women, Family and Childhood and the Ministry of Defense was established, and the responsiveness of law enforcement and health care personnel to requests for help in the face of domestic violence has also increased. A detailed reminder of the support structures was attached to the survey of all the participants.

In our study, psychological violence appeared to be the most frequent type of violence (96\%). Almost all the abused women experienced it, followed by economic (41\%) and then physical violence (10\%). The large majority of those who experienced violence during the lockdown did not report it. None of the women who experienced emotional abuse reported it. As it is the case in many countries especially developing ones, Tunisia has patriarchal and religious societal norms conducive to the normalization of gender-based violence (Zgueb et al. 2019). As a matter of fact, more than half of Tunisian women interviewed in 2016 said violence is ordinary and not worth reporting (UNFPA 2017).

As seen in our results, women who have higher rates of distress are more likely to have a problematic Facebook Use. We found that $40 \%$ of our sample meet the definition of a Facebook addiction. Addictive disorders are a frequent comorbidity of anxiety and depressive disorders (WolitzkyTaylor and Schiffman 2019). In addition, during lockdown, Facebook use scores appear to be higher among those abused as shown in Table 5. To conclude, it seems that women abused during lockdown find refuge in a problematic use of 
Table 4 Violence and Facebook addiction scores association

\begin{tabular}{|c|c|c|c|}
\hline & \multicolumn{3}{|c|}{ Violence during COVID-19 lockdown } \\
\hline$n(\%)$ & $\begin{array}{l}-\mathrm{No} \\
\quad 640(85.2 \%)\end{array}$ & $\begin{array}{l}\text { Yes } \\
111(14.8 \%)\end{array}$ & $p$ \\
\hline Facebook addiction score $\mathrm{M}( \pm \mathrm{SD})$ & $16 \pm 5.25$ & $18.9 \pm 5.57$ & $<0.001$ \\
\hline
\end{tabular}

$\mathrm{M}( \pm \mathrm{SD}):$ Mean $\pm($ standard deviation $)$ social media. Use which appears to be problematic under normal conditions may have been seen as a useful and protective tool from the COVID-19 during lockdown. No studies on the association between domestic violence during the COVID-19 pandemic and social media addiction were found; our article is the first to examine this association. A study conducted in China involving 908 participants of both sexes and ages overlapping with the participants in our sample found that behavioral addiction to telephone and internet use was noted in people suffering from depressive and anxiety symptoms due to COVID-19. However, the severity of problematic smartphone and internet use was not associated with exposure to information about the COVID-19 pandemic. The authors suggested that smartphone and internet use may be part of coping strategies implemented for the emotional distress secondary to this pandemic (Elhai et al. 2020).

The effects on mental health of emerging infectious diseases in the world over the last decade may give us an idea about the long-term impact of the current COVID-19 pandemic. This can be seen in the psychological distress and guilt that Zika virus disease has generated since 2013, and to this day in mothers of newborn babies with congenital malformations (Tucci et al. 2017). The same goes for the Ebola virus that emerged in 2010, and that generated post-traumatic stress disorder among the survivors in Sierra Leone (Paladino et al. 2017).

Since Tunisia's independence in 1956, the country's policy had been geared towards empowering women and protecting their rights. Nonetheless, and even though Tunisia is often praised for its remarkable achievements for women in terms of constitutional human rights (Megahed and Lack 2011),

Table 5 Association between violence before and during lockdown

\begin{tabular}{lll}
\hline & $\begin{array}{l}\text { No violence } \\
\text { during } \\
\text { lockdown } \\
(n=640)\end{array}$ & $\begin{array}{l}\text { Violence } \\
\text { during } \\
\text { lockdown } \\
(n=111)\end{array}$ \\
\hline $\begin{array}{c}\text { No history of domestic violence } \\
\text { before the pandemic }(n=718)\end{array}$ & 631 & 87 \\
$\begin{array}{c}\text { History of domestic violence } \\
\text { before the pandemic }(n=33)\end{array}$ & 9 & 24 \\
\hline
\end{tabular}

$(N=751)$ gender-based violence persists and continues to be a major problem rooted in the Tunisian society, as in most Eastern and Western societies alike.

Strengths and limitations of the study To our knowledge, this is the first study that evaluates the acute impact of COVID-19 on mental health and violence among women in Tunisia, Africa, and the Arab world. It therefore provides considerable information in view of the cultural particularities of the region. This data could be used to establish appropriate intervention strategies. On the other hand, the possibility of selection bias should be considered as our sample method (snowball) could limit the generalizability of our results. In addition, we were limited to assessing participants who had access to the Internet and who some knowledge of computer use. Given the exceptional conditions of lockdown and social distancing, the snowball sampling strategy was the only one possible. Moreover, $80 \%$ of participants were between 26 and 45 years old, and $40 \%$ had a university education (percentage that is higher than official figures showing that $14.8 \%$ of Tunisian females above 25 had completed at least a short-cycle tertiary education in 2016) (The World Bank 2016). The characteristics of our sample in terms of age and education might hinder the generalizability of our findings to all women in Tunisia and in the region.

\section{Conclusion}

To our knowledge, this is the first study that evaluates the acute impact of COVID-19 on mental health and violence among women in Tunisia, Africa, and the Arab world. It therefore provides considerable information in view of the cultural particularities of the region. In fact, it may be a sound basis for developing a more effective psychological intervention aimed at women in these regions. Strengthening strategies to protect women during periods of crisis is urgent. However, a change in mentalities would take more time to set up. Violence against women necessitates a fundamental long-term struggle and practical intervention strategies. These changes must emanate from within societies themselves and not be imposed in order to effectively change mentalities. This starts with education within the family core and requires collaboration 
between civil society and government to promote real longlasting changes.

Acknowledgments The authors thank all participants.

Authors' contributions Sabrine Sediri and Yosra Zgueb designed the review. Sami Ouanes, Uta Ouali, Soumaya Bourgou, Rabaa jomli, and Fathi Nacef provided substantial input to the manuscript. All authors critically reviewed drafts and approved the content of the manuscript.

\section{Compliance with ethical standards}

Conflict of interest The authors declare that they have no conflict of interest.

Consent to participate Informed consent was obtained from all individual participants included in the study.

\section{References}

Adhikari SP, Meng S, Wu Y-J, Mao YP, Ye RX, Wang QZ, Sun C, Sylvia S, Rozelle S, Raat H, Zhou H (2020) Epidemiology, causes, clinical manifestation and diagnosis, prevention and control of coronavirus disease (COVID-19) during the early outbreak period: a scoping review. Infect Dis Poverty 9:29. https://doi.org/10.1186/ s40249-020-00646-x

Akiskal KK, Akiskal HS (2005) The theoretical underpinnings of affective temperaments: implications for evolutionary foundations of bipolar disorder and human nature. J Affect Disord 85:231-239. https://doi.org/10.1016/j.jad.2004.08.002

Ali AM, Ahmed A, Sharaf A, Kawakami N, Abdeldayem SM, Green J (2017) The Arabic version of the Depression Anxiety Stress Scale21: cumulative scaling and discriminant-validation testing. Asian J Psychiatr 30:56-58. https://doi.org/10.1016/j.ajp.2017.07.018

Andreassen CS, Torsheim T, Brunborg GS, Pallesen S (2012) Development of a Facebook Addiction Scale. Psychol Rep 110: 501-517. https://doi.org/10.2466/02.09.18.PR0.110.2.501-517

Banerjee DD (2020) The other side of COVID-19: impact on obsessive compulsive disorder (OCD) and hoarding. Psychiatry Res 288: 112966. https://doi.org/10.1016/j.psychres.2020.112966

Bellizzi S, Nivoli A, Lorettu L, Ronzoni AR (2020) Human rights during the COVID-19 pandemic: the issue of female genital mutilations. Public Health 185:53-54. https://doi.org/10.1016/j.puhe.2020.05. 037

Brooks SK, Webster RK, Smith LE, Woodland L, Wessely S, Greenberg N, Rubin GJ (2020) The psychological impact of quarantine and how to reduce it: rapid review of the evidence. Lancet 395:912920. https://doi.org/10.1016/S0140-6736(20)30460-8

Campbell AM (2020) An increasing risk of family violence during the Covid-19 pandemic: strengthening community collaborations to save lives. Forensic Sci Int: Reports 2:100089. https://doi.org/10. 1016/j.fsir.2020.100089

Chatterjee SS, Barikar CM, Mukherjee A (2020) Impact of COVID-19 pandemic on pre-existing mental health problems. Asian J Psychiatr 51:102071. https://doi.org/10.1016/j.ajp.2020.102071

Devries KM, Mak JYT, García-Moreno C, Petzold M, Child JC, Falder G, Lim S, Bacchus LJ, Engell RE, Rosenfeld L, Pallitto C, Vos T, Abrahams N, Watts CH (2013) Global health. The global prevalence of intimate partner violence against women. Science 340:15271528. https://doi.org/10.1126/science.1240937

Elhai JD, Yang H, McKay D, Asmundson GJG (2020) COVID-19 anxiety symptoms associated with problematic smartphone use severity in Chinese adults. J Affect Disord 274:576-582. https://doi.org/10. 1016/j.jad.2020.05.080

General Assembly of the World Medical Association (2014) World medical association declaration of Helsinki: ethical principles for medical research involving human subjects. J Am Coll Dent 81:14-18

Ghali H, Ghammem R, Zammit N, Fredj SB, Ammari F, Maatoug J, Ghannem H (2019) Validation of the Arabic version of the Bergen Facebook Addiction Scale in Tunisian adolescents. Int J Adolesc Med Health. https://doi.org/10.1515/ijamh-2019-0077

Gracia E (2004) Unreported cases of domestic violence against women: towards an epidemiology of social silence, tolerance, and inhibition. J Epidemiol Community Health 58:536-537. https://doi.org/10. 1136/jech.2003.019604

Liu N, Zhang F, Wei C, Jia Y, Shang Z, Sun L, Wu L, Sun Z, Zhou Y, Wang Y, Liu W (2020) Prevalence and predictors of PTSS during COVID-19 outbreak in China hardest-hit areas: gender differences matter. Psychiatry Res 287:112921. https://doi.org/10.1016/j. psychres.2020.112921

Mapayi B, Makanjuola ROA, Mosaku SK, Adewuya OA, Afolabi O, Aloba OO, Akinsulore A (2013) Impact of intimate partner violence on anxiety and depression amongst women in Ile-Ife, Nigeria. Arch Womens Ment Health 16:11-18. https://doi.org/10.1007/s00737012-0307-x

Marques ES, de Moraes CL, Hasselmann MH et al (2020) Violence against women, children, and adolescents during the COVID-19 pandemic: overview, contributing factors, and mitigating measures. Cad Saude Publica 36:e0074420. https://doi.org/10.1590/0102$311 X 00074420$

Mazza M, Marano G, Lai C, Janiri L, Sani G (2020) Danger in danger: interpersonal violence during COVID-19 quarantine. Psychiatry Res 289:113046. https://doi.org/10.1016/j.psychres.2020.113046

Megahed N, Lack S (2011) Colonial legacy, women's rights and gendereducational inequality in the Arab world with particular reference to Egypt and Tunisia. Int Rev Educ 57:397-418. https://doi.org/10. 1007/s11159-011-9215-y

Mengin A, Allé MC, Rolling J, Ligier F, Schroder C, Lalanne L, Berna F, Jardri R, Vaiva G, Geoffroy PA, Brunault P, Thibaut F, Chevance A, Giersch A (2020) Psychopathological consequences of confinement. Encephale. 46:S43-S52. https://doi.org/10.1016/j.encep. 2020.04.007

Oram S, Khalifeh H, Howard LM (2017) Violence against women and mental health. Lancet Psychiatry 4:159-170. https://doi.org/10. 1016/S2215-0366(16)30261-9

Paladino L, Sharpe RP, Galwankar SC, Sholevar F, Marchionni C, Papadimos TJ, Paul E, Hansoti B, Firstenberg M, Garg M, Watson M, Baxter RA, Stawicki SP, American College of Academic International Medicine (ACAIM) (2017) Reflections on the Ebola public health emergency of international concern, part 2: the unseen epidemic of posttraumatic stress among health-care personnel and survivors of the 2014-2016 Ebola outbreak. J Global Infect Dis 9: 45-50. https://doi.org/10.4103/jgid.jgid_24_17

Röhr S, Müller F, Jung F, Apfelbacher C, Seidler A, Riedel-Heller SG (2020) Psychosocial impact of quarantine measures during serious coronavirus outbreaks: a rapid review. Psychiatr Prax 47:179-189. https://doi.org/10.1055/a-1159-5562

Stöckl H, Devries K, Rotstein A, Abrahams N, Campbell J, Watts C, Moreno CG (2013) The global prevalence of intimate partner homicide: a systematic review. Lancet 382:859-865. https://doi.org/10. 1016/S0140-6736(13)61030-2

The World Bank, 2016. The World Bank open data 2016 https:/data. worldbank.org/indicator/SE.TER.CUAT.ST.FE.ZS?locations=TN. Accessed 26 August 2020

Tian F, Li H, Tian S, Yang J, Shao J, Tian C (2020) Psychological symptoms of ordinary Chinese citizens based on SCL-90 during the level I emergency response to COVID-19. Psychiatry Res 288: 112992. https://doi.org/10.1016/j.psychres.2020.112992 
Tran TD, Tran T, Fisher J (2013) Validation of the depression anxiety stress scales (DASS) 21 as a screening instrument for depression and anxiety in a rural community-based cohort of northern Vietnamese women. BMC Psychiatry 13:24. https://doi.org/10.1186/1471244X-13-24

Tucci V, Moukaddam N, Meadows J, Shah S, Galwankar SC, Kapur GB (2017) The forgotten plague: psychiatric manifestations of Ebola, Zika, and emerging infectious diseases. J Global Infect Dis 9:151156. https://doi.org/10.4103/jgid.jgid_66_17

Tunisian Republic Presidency, 2020. President activities during March 2020. http://www.carthage.tn/?q=ar/event-created/month/ 2020-03. Accessed 26 August 2020

UNFPA, 2017. Programme conjoint: Pour l'amélioration de la prise en charge des femmes et des filles victimes de violence. https://www. unfpa.org/data/transparency-portal/unfpa-tunisia. Accessed 26 August 2020

Verma R, Balhara YPS, Gupta CS (2011) Gender differences in stress response: role of developmental and biological determinants. Ind Psychiatry J 20:4-10. https://doi.org/10.4103/0972-6748.98407

Vigouroux SL, Scola C (2018) Differences in parental burnout: influence of demographic factors and personality of parents and children. Front Psychol 9:887. https://doi.org/10.3389/fpsyg.2018.00887

Wang C, Pan R, Wan X et al (2020) Immediate psychological responses and associated factors during the initial stage of the 2019 coronavirus disease (COVID-19) epidemic among the general population in
China. Int J Environ Res Public Health 17:1729. https://doi.org/10. 3390/ijerph17051729

Wang J, Korczykowski M, Rao H, Fan Y, Pluta J, Gur RC, McEwen BS, Detre JA (2007) Gender difference in neural response to psychological stress. Soc Cogn Affect Neurosci 2:227-239. https://doi.org/10. 1093/scan/nsm018

Wenham C, Smith J, Morgan R, Gender and COVID-19 Working Group (2020) COVID-19: the gendered impacts of the outbreak. Lancet 395:846-848. https://doi.org/10.1016/S0140-6736(20)30526-2

Wolitzky-Taylor K, Schiffman J (2019) Predictive associations among the repeated measurements of anxiety, depression, and craving in a dual diagnosis program. J Dual Diagn 15:140-146. https://doi.org/ 10.1080/15504263.2019.1589660

Zgueb Y, Bourgou S, Neffeti A, Amamou B, Masmoudi J, Chebbi H, Somrani N, Bouasker A (2020) Psychological crisis intervention response to the COVID 19 pandemic: a Tunisian centralised protocol. Psychiatry Res 289:113042. https://doi.org/10.1016/j.psychres. 2020.113042

Zgueb Y, Ouali U, Achour R, Jomli R, Nacef F (2019) Cultural aspects of vaginismus therapy: a case series of Arab-Muslim patients. Cogn Behav Ther 12:e3. https://doi.org/10.1017/S1754470X18000119

Publisher's note Springer Nature remains neutral with regard to jurisdictional claims in published maps and institutional affiliations. 